\title{
Central review of cytogenetics is necessary for cooperative group correlative and clinical studies of adult acute leukemia: The Cancer and Leukemia Group B experience
}

\author{
KRZYSZTOF MRÓZEK ${ }^{1}$, ANDREW J. CARROLL ${ }^{2}$, KATI MAHARRY ${ }^{1,3}$, KATHLEEN W. RAO $^{4}$, \\ SHIVANAND R. PATIL ${ }^{5}$, MARK J. PETTENATI ${ }^{6}$, MICHAEL S. WATSON ${ }^{7}$, DIANE C. ARTHUR ${ }^{8}$, \\ RAMANA TANTRAVAHI ${ }^{9}$, NYLA A. HEEREMA ${ }^{10}$, PRASAD R.K. KODURU ${ }^{11}$, \\ ANNEMARIE W. BLOCK ${ }^{12}$, MAZIN B. QUMSIYEH ${ }^{13}$, COLIN G. EDWARDS ${ }^{1}$, \\ LISA J. STERLING ${ }^{1}$, KELSI B. HOLLAND ${ }^{1,3}$ and CLARA D. BLOOMFIELD ${ }^{1}$ \\ ${ }^{1}$ Division of Hematology and Oncology, Department of Internal Medicine, Comprehensive Cancer Center, \\ The Ohio State University, Columbus, $\mathrm{OH} ;{ }^{2}$ University of Alabama at Birmingham, Birmingham, AL; \\ ${ }^{3}$ The CALGB Statistical Center, Duke University Medical Center, Durham; ${ }^{4}$ University of North Carolina at Chapel Hill, \\ Chapel Hill, NC; ${ }^{5}$ University of Iowa, Iowa City, IA; ${ }^{6}$ Wake Forest University Medical Center, Winston Salem, NC; \\ ${ }^{7}$ American College of Medical Genetics, Bethesda, MD; ${ }^{8}$ National Cancer Institute, Bethesda, MD; ${ }^{9}$ Dana-Farber Cancer \\ Institute, Boston, MA; ${ }^{10}$ Department of Pathology, Comprehensive Cancer Center, The Ohio State University, \\ Columbus, OH; ${ }^{11}$ North Shore University Hospital, Manhasset, NY; ${ }^{12}$ Roswell Park Cancer Institute, \\ Buffalo, NY; ${ }^{13}$ Duke University Medical Center, Durham, NC, USA
}

Received March 21, 2008; Accepted April 18, 2008

DOI: 10.3892/ijo_00000002

\begin{abstract}
The Cancer and Leukemia Group B has performed central review of karyotypes submitted by institutional cytogenetics laboratories from patients with acute myeloid (AML) and acute lymphoblastic (ALL) leukemia since 1986. We assessed the role of central karyotype review in maintaining accurate, high quality cytogenetic data for clinical and translational studies using two criteria: the proportion of karyotypes rejected (i.e. inadequate), and, among accepted (i.e. adequate) cases, the proportion of karyotypes whose interpretation was changed on central karyotype review. We compared the first four years during which central karyotype review was performed with a recent 4-year period and found that the proportion of rejected samples decreased significantly for both AML and ALL. However, during the latter period, central karyotype reviews still found $8 \%$ of AML and $16 \%$ of ALL karyotypes inadequate. Among adequate cases, the karyotype was revised in $26 \%$ of both AML and

Correspondence to: Dr Krzysztof Mrózek, Division of Hematology and Oncology and the Comprehensive Cancer Center, The Arthur G. James Cancer Hospital and Richard J. Solove Research Institute, Room 1248B, The Ohio State University, 300 West Tenth Avenue, Columbus, OH 43210-1228, USA

E-mail: krzysztof.mrozek@osumc.edu
\end{abstract}

Key words: karyotyping, chromosome aberrations, human, correlative studies, acute leukemia
ALL samples. Some revisions resulted in changing the patients assignment to particular World Health Organization diagnostic categories and/or moving patients from one prognostic group to another. Overall, when both data on rejection rates and data on karyotype revisions made in accepted cases were considered together, $32 \%$ of AML and $38 \%$ of ALL samples submitted were either rejected or revised on central karyotype review during the recent 4 -year period. These data underscore the necessity of continued central karyotype review in multiinstitutional cooperative group studies.

\section{Introduction}

Cytogenetic findings have become an integral part of diagnosis, prognostication and therapeutic stratification of acute myeloid leukemia (AML) and acute lymphoblastic leukemia (ALL). Such recurrent chromosome abnormalities and their molecular equivalents as $\mathrm{t}(8 ; 21)(\mathrm{q} 22 ; \mathrm{q} 22) / R U N X 1-R U N X 1 T 1, \operatorname{inv}(16)$ (p13q22)/t(16;16)(p13;q22)/CBFB-MYH11, t(15;17)(q22; q12-21)/PML-RARA, and balanced abnormalities involving band 11q23 and the MLL gene are now included in the World Health Organization (WHO) classification of AML, and together with morphology, immunophenotype and clinical features are being used to define distinct disease entities (1). Notably, the role of cytogenetics will be substantially increased in the 2008 revision of the WHO classification (2).

Moreover, pretreatment cytogenetic findings constitute one of the most important prognostic factors in both AML (3-10) and ALL (7,11-13), are used to determine postremission therapy (14-17), and are important for molecular genetic studies investigating mutations (18-29) and changes 
in expression of specific genes (30-32), as well as gene- (33-37) and microRNA-expression $(38,39)$ profiles in patients with acute leukemias. Importantly, the National Comprehensive Cancer Network (NCCN) Clinical Practice Guidelines in Oncology specify that cytogenetic analysis is an obligatory part of the diagnostic workup in AML (40). Likewise, cytogenetic analysis is one of the minimum laboratory requirements for the diagnosis of AML according to the 'Guidelines on the Management of Acute Myeloid Leukaemia in Adults' issued by the British Committee for Standards in Haematology (41). Consequently, the Cancer and Leukemia Group B (CALGB) now mandates cytogenetic analyses for adult AML and ALL front-line treatment trials and many correlative studies. It is therefore imperative that cytogenetic data are accurate.

Despite continuous improvements in cytogenetic methodology, not all cytogenetic studies of bone marrow (BM) or blood from patients with acute leukemia are successful. In addition to a fraction of cases in which BM or blood cultures yield no mitotic cells, some cytogenetic preparations from leukemic samples are of suboptimal quality. This can make correct interpretation of karyotypes difficult. It has long been recognized that metaphase chromosomes of leukemic cells (especially, but not exclusively, from ALL patients) often have poor morphology with indistinct banding (42). Furthermore, a remarkable heterogeneity of chromosome findings in acute leukemias, with over two hundred recognized recurrent aberrations, many of which are relatively rare having been reported in $<10$ cases worldwide (43-45), underscores the necessity for cytogeneticists analyzing patients with AML and ALL to have vast experience in leukemia cytogenetics.

Therefore, CALGB pioneered the central review of karyotypes, which has been performed biannually since 1986 (46). In the current study, we evaluated the role of central karyotype review in providing accurate cytogenetic data. Our analysis shows an improvement in the quality of submitted karyotypes over time but also confirms the continued need for performing central karyotype review in the multi-institutional cooperative group setting to obtain the best possible data for clinical and translational studies.

\section{Patients and methods}

Cytogenetic analyses of diagnostic $(n=5259)$ and relapse $(n=909)$ samples from patients with AML and ALL enrolled onto a prospective cytogenetic companion study, CALGB 8461 (5), were performed in multiple, currently 33, CALGBapproved institutional cytogenetic laboratories. Written IRBapproved informed consent was obtained from all patients. For each specimen, two karyotypes and metaphase spreads from each clone were submitted with the data on processing methods to the CALGB Cytogenetic Data Management Center. If applicable, images of interphase and/or metaphase cells subjected to fluorescence in situ hybridization (FISH) were also submitted. All cases underwent biannual central karyotype review performed by the CALGB Karyotype Review Committee consisting of ten expert cancer cytogeneticists. At central karyotype review sessions, every karyotype, metaphase spread, FISH image, and processing and interpretive data were reviewed by two cytogeneticists. In some cases, usually those with more complex chromosome abnormalities and/or with suboptimal banding quality, other reviewers also rendered their opinion. Once consensus was reached, each submission was judged as either acceptable with adequate banding quality, acceptable with borderline banding quality, or inadequate and consequently rejected. Reasons for rejection included poor banding quality that makes unequivocal karyotype interpretation impossible, and, only in cases with a normal karyotype, analysis of $<20$ metaphase cells from a marrow sample cultured for $24-48 \mathrm{~h}$ or analysis of blood only (5). Since the aim of this study was to assess the role of central karyotype review, our analyses did not include 202 AML and 125 ALL cases for whom cytogenetic analysis yielded no metaphase cells.

In addition to data on rejection rates collected routinely at each central karyotype review, for the purpose of this study, we prospectively collected detailed information on the reasons for revisions made by central karyotype review in the submitted karyotypes that were accepted or borderline accepted during eight recent central karyotype review sessions. The reasons for revision were divided into the following categories: i) major errors in karyotype interpretation, such as failure of the submitting laboratory to recognize a clonal abnormality, identification of an abnormality found on central karyotype review not to be present, and incorrect interpretation of an abnormality; ii) the need for refinement of breakpoint assignment in structural abnormalities properly recognized by the submitting laboratory, iii) misidentified or upside-down chromosomes, and iv) incorrect use of the ISCN (1995) nomenclature (47). In this study, we excluded samples analyzed cytogenetically during complete remission, because these samples differ from pretreatment and relapse samples in that they rarely contain leukemic cells and are usually karyotypically normal (48). The rejection rates between the first and the recent 4-year periods (Table I) have been compared using the Fisher's exact test. All analyses were performed by the CALGB Statistical Center.

\section{Results and Discussion}

Table I shows rejection rates and reasons for rejection for AML and ALL specimens that underwent central karyotype review during the entire period between 1986 and 2006. Overall, $12 \%$ of 4991 AML and $23 \%$ of 1177 ALL karyotypes submitted were rejected. The most common reason for rejection was inadequate banding quality, which accounted for rejection of 53\% (325 of 612) of AML and 46\% (123 of 270) of ALL inadequate cases. When we compared rejection rates between the first four years during which central karyotype review was performed and the recent 4-year period, we found a significant improvement in the quality of submitted specimens in both AML $(\mathrm{P}<0.0001)$ and ALL $(\mathrm{P}<0.001)$. This was mainly due to the significant decrease in the numbers of karyotypes with inadequate banding quality (AML, $\mathrm{P}<0.0001$ and ALL, $\mathrm{P}=0.02$ ). Nevertheless, the recent central karyotype reviews still found $8 \%$ of AML and $16 \%$ of ALL samples inadequate.

Another indication of the quality improvement over time was an increase in the proportion of abnormal karyotypes pretreatment, from $52 \%$ in the first 4 years to $57 \%$ in the recent 4 years $(\mathrm{P}=0.05)$ in $\mathrm{AML}$ and from 59 to $75 \%$ in ALL 
Table I. Rejection rates and reasons for rejection by central karyotype review among AML and ALL cases enrolled onto CALGB 8461.

\begin{tabular}{|c|c|c|c|c|c|}
\hline Disease & Reason for rejection & All samples & First 4 years & Recent 4 years & P-value ${ }^{a}$ \\
\hline \multirow{5}{*}{ AML } & No. of samples reviewed & 4991 & 934 & 1126 & \\
\hline & No. $(\%)$ of samples rejected & $612(12)^{b}$ & $196(21)^{\mathrm{b}}$ & $90(8)^{b}$ & $<0.0001$ \\
\hline & Inadequate banding $(\%)$ & $325(53)$ & $149(76)$ & $26(29)$ & $<0.0001$ \\
\hline & Normal BM karyotype and $<20$ cells $(\%)^{\mathrm{c}}$ & $168(27)$ & $20(10)$ & $40(44)$ & $<0.0001$ \\
\hline & Normal karyotype in blood only $(\%)^{\mathrm{d}}$ & $115(19)$ & $26(13)$ & $23(26)$ & 0.02 \\
\hline \multirow[t]{5}{*}{ ALL } & No. of samples reviewed & 1177 & 222 & 128 & \\
\hline & No. $(\%)$ of samples rejected & $270(23)$ & $74(33)$ & $20(16)$ & $<0.001$ \\
\hline & Inadequate banding (\%) & $123(46)$ & $49(66)$ & $7(35)$ & 0.02 \\
\hline & Normal BM karyotype and $<20$ cells $(\%)^{\mathrm{c}}$ & $78(29)$ & $13(18)$ & $9(45)$ & 0.02 \\
\hline & Normal karyotype in blood only $(\%)^{\mathrm{d}}$ & $69(26)$ & $12(16)$ & $4(20)$ & 0.74 \\
\hline
\end{tabular}

${ }^{a}$ Comparisons of the rejection rates between the first 4 years and the recent 4 years of central karyotype reviews were calculated using

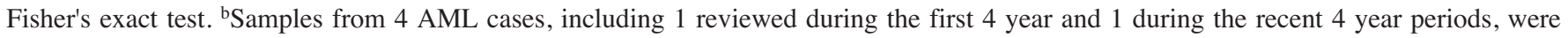
rejected due to the inability of the submitting laboratory to provide sufficient documentation for suspected abnormalities. ${ }^{\mathrm{c}} \mathrm{BM}$ denotes bone marrow. ${ }^{\mathrm{d} C y t o g e n e t i c ~ a n a l y s i s ~ o f ~ b o n e ~ m a r r o w ~ w a s ~ e i t h e r ~ n o t ~ p e r f o r m e d ~ o r ~ w a s ~ u n s u c c e s s f u l . ~}$

Table II. Changes in karyotype interpretation made in accepted AML and ALL cases during 8 recent central karyotype review sessions.

\begin{tabular}{|c|c|c|c|}
\hline $\begin{array}{l}\text { Changes in karyotype interpretation } \\
\text { made by central karyotype review }\end{array}$ & $\begin{array}{c}\text { Total } \\
\mathrm{n}=1138\end{array}$ & $\begin{array}{c}\text { AML } \\
n=1031\end{array}$ & $\begin{array}{c}\text { ALL } \\
\mathrm{n}=107\end{array}$ \\
\hline No. $(\%)$ of samples revised ${ }^{a}$ & $300(26)$ & $272(26)$ & $28(26)$ \\
\hline Total no. of changes made ${ }^{a}$ & 446 & 404 & 42 \\
\hline \multicolumn{4}{|l|}{ Type of revision } \\
\hline $\begin{array}{l}\text { Recognition of a missed abnormality or change } \\
\text { in abnormality description }(\%)\end{array}$ & $195(44)$ & $176(43)$ & $19(45)$ \\
\hline Change in breakpoint(s) assignment (\%) & $100(22)$ & $83(21)$ & $17(40)$ \\
\hline Correction of misidentified or upside-down chromosome(s) (\%) & $98(22)$ & $95(24)$ & $3(7)$ \\
\hline Correction in ISCN (1995) nomenclature (\%) & $53(12)$ & $50(12)$ & $3(7)$ \\
\hline
\end{tabular}

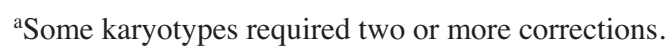

$(\mathrm{P}=0.007)$. These improvements in quality can be attributed to many factors, including progress in cell culturing, harvesting and banding techniques, as well as increase in proficiency in analyzing specimens from patients with acute leukemias. The latter has been achieved in part through feedback provided to cytogeneticists from the submitting laboratories after central karyotype review sessions and through educational workshops organized and conducted by the members of the Karyotype Review Committee during CALGB Group Meetings.

Among karyotypes deemed to have adequate banding at 8 recent Central Karyotype Review sessions, changes in karyotype interpretation were made in $26 \%$ of both AML and ALL cases (Table II). The revisions included identification of an unrecognized chromosome abnormality or reinterpretation of an abnormality incorrectly interpreted by the submitting laboratory (44\% of all revisions), reassignment of breakpoints in structural aberrations (22\%), correction of misidentified or upside-down chromosomes (22\%), and correction of errors in the ISCN (1995) nomenclature (12\%).

In several instances, major changes in karyotype interpretation made on central karyotype review resulted in moving patients from one diagnostic category in the current 
WHO classification (1) to another. For example, AML patients whose karyotypes submitted as normal were revised to abnormal ones that harbored $t(9 ; 11)(\mathrm{p} 22 ; \mathrm{q} 23)$, $\mathrm{t}(11 ; 19)(\mathrm{q} 23 ; \mathrm{p} 13.1)$ or inv(16)(p13q22), as well as patients whose submitted karyotype was changed from $46, X,-Y,+8$ to $46, X,-Y,+8, t(9 ; 11)(p 22 ; q 23)$, from 46,XX,t(10;11)(p14;q13) to $46, X X$,ins $(10 ; 11)(\mathrm{p} 12 ; q 23 q 13)$, from $46, X Y, \operatorname{del}(5)$ (q13q33),del(11)(q23) to 46,XY, $\operatorname{del}(5)(q 13 q 33), t(6 ; 11)$ $(\mathrm{q} 27 ; \mathrm{q} 23)$, and from 46,XY, del(3)(p13), add(11)(q23),-18,$21,+$ mar to $46, X Y, t(3 ; 11)(p 13 ; q 23)$, add(18)(q21),-21 would be reclassified from having 'AML not otherwise categorized' to 'AML with recurrent cytogenetic abnormalities'. Conversely, the patient whose submitted complex karyotype included an inv(16)(p13q22) that was revised on central karyotype review to $\operatorname{der}(16) \operatorname{add}(16)(\mathrm{p} 13) \operatorname{del}(16)(\mathrm{q} 22)$ would be reclassified from having 'AML with recurrent cytogenetic abnormalities' to 'AML not otherwise categorized'. There would be multiple additional changes in diagnostic categories once the new 2008 edition of the WHO classification (2) is published, including, for example, a reclassification from 'AML with myelodysplasia related changes' to 'AML with recurrent genetic abnormalities' for the patient whose karyotype submitted as normal was found on central karyotype review to contain an inv(3)(q21q26).

Many of both the aforementioned and other karyotype revisions made on central karyotype review resulted in changes in prognostic group assignment of the patients. For instance, revisions from a normal karyotype to a karyotype containing $\operatorname{inv}(3)(\mathrm{q} 21 \mathrm{q} 26)$ or $\mathrm{t}(11 ; 19)(\mathrm{q} 23 ; \mathrm{p} 13.1)$, or from $\operatorname{del}(11)(\mathrm{q} 23)$ to $t(6 ; 11)(\mathrm{q} 27 ; \mathrm{q} 23)$ meant that these patients were no longer classified as having an intermediate risk but were included in the adverse risk category instead (5). Poor prognosis associated with an isolated trisomy of chromosome 13 (49) was no longer predicted in a patient whose karyotype was revised from $47, \mathrm{XY},+13$ to $47, \mathrm{XY},+15$ when the reviewers discovered that an extra chromosome submitted as chromosome 13 was in fact an extra chromosome 15 placed upsidedown in the karyotype of borderline quality. To date, prognostic significance of isolated trisomy 15 is unclear and it has been suggested to represent a benign, age-related abnormality in older male patients $(50,51)$. Moreover, identification of an initially unrecognized inv(16) alters the patient's risk assignment from intermediate to favorable, whereas revision of the submitted inv(16) to $\operatorname{der}(16) \operatorname{add}(16)(\mathrm{p} 13) \operatorname{del}(16)(\mathrm{q} 22)$ as part of a complex karyotype means that the patient's risk-group assignment is no longer favorable but becomes adverse. Importantly, documentation of the presence or absence of inv(16) is of major clinical importance (52) because the postremission therapy of AML patients with $\operatorname{inv}(16)$ on CALGB protocols is administered in a risk-adapted fashion and includes three courses of high-dose cytarabine, whereas patients without inv(16) [or $\mathrm{t}(8 ; 21)]$ receive autologous peripheral stem-cell transplantation (15).

Finally, we evaluated both the data on karyotype revisions made in the accepted cases and data on rejection rates during the recent 4-year period. Overall, 32\% of AML and 38\% of ALL samples submitted were either rejected or revised on central karyotype review.

While several studies have addressed the issue of proficiency testing and quality control in clinical cytogenetics
(53-55), to our knowledge only one other study (from the Children's Oncology Group), published in abstract form, has reported the cooperative group experience concerning central review of karyotypes from acute leukemia patients (Heerema, et al, Cytogenet Genome Res 106: 136, 2004). Results of this study are remarkably similar to ours, showing that the karyotype was either changed or rejected in $31 \%$ of AML and $49 \%$ of ALL pediatric cases submitted. Therefore, we conclude that central karyotype review plays a vital role in ensuring the validity of the clinical trials and correlative studies conducted by both adult and children's cooperative groups.

\section{Acknowledgments}

This study was supported in part by National Cancer Institute, Bethesda, MD grants CA77658, CA101140, CA31946, CA16058, CA47545, CA47559, CA47642, CA77440, CA16450, CA32291, CA35279, CA47577 and CA02599, and The Coleman Leukemia Research Foundation.

\section{References}

1. Jaffe ES, Harris NL, Stein H and Vardiman JW (eds.): World Health Organization classification of tumours. Pathology and genetics of tumours of haematopoietic and lymphoid tissues. IARC Press, Lyon, 2001.

2. Swerdlow S, Campo E, Harris NL, Jaffe ES, Pileri S, Stein H, Thiele J and Vardiman JW (eds.): World Health Organization classification of tumours. Pathology and genetics of tumours of haematopoietic and lymphoid tissues. IARC Press, Lyon (In press).

3. Grimwade D, Walker H, Oliver F, et al: The importance of diagnostic cytogenetics on outcome in AML: analysis of 1,612 patients entered into the MRC AML 10 trial. Blood 92: 2322-2333, 1998.

4. Slovak ML, Kopecky KJ, Cassileth PA, et al: Karyotypic analysis predicts outcome of preremission and postremission therapy in adult acute myeloid leukemia: a Southwest Oncology Group/Eastern Cooperative Oncology Group study. Blood 96: 4075-4083, 2000.

5. Byrd JC, Mrózek K, Dodge RK, et al: Pretreatment cytogenetic abnormalities are predictive of induction success, cumulative incidence of relapse, and overall survival in adult patients with de novo acute myeloid leukemia: results from Cancer and Leukemia Group B (CALGB 8461). Blood 100: 4325-4336, 2002.

6. Haferlach T, Kern W, Schoch C, et al: A new prognostic score for patients with acute myeloid leukemia based on cytogenetics and early blast clearance in trials of the German AML Cooperative Group. Haematologica 89: 408-418, 2004.

7. Mrózek K, Heerema NA and Bloomfield CD: Cytogenetics in acute leukemia. Blood Rev 18: 115-136, 2004.

8. Fröhling S, Schlenk RF, Kayser S, Morhardt M, Benner A, Döhner K and Döhner H: Cytogenetics and age are major determinants of outcome in intensively treated acute myeloid leukemia patients older than 60 years: results from AMLSG trial AML HD98-B. Blood 108: 3280-3288, 2006.

9. Farag SS, Archer KJ, Mrózek K, et al: Pretreatment cytogenetics add to other prognostic factors predicting complete remission and long-term outcome in patients 60 years of age or older with acute myeloid leukemia: results from Cancer and Leukemia Group B 8461. Blood 108: 63-73, 2006.

10. Armand P, Kim HT, De Angelo DJ, et al: Impact of cytogenetics on outcome of de novo and therapy-related AML and MDS after allogeneic transplantation. Biol Blood Marrow Transplant 13: 655-664, 2007.

11. Wetzler M, Dodge RK, Mrózek K, et al: Prospective karyotype analysis in adult acute lymphoblastic leukemia: the Cancer and Leukemia Group B experience. Blood 93: 3983-3993, 1999.

12. Mancini M, Scappaticci D, Cimino G, et al: A comprehensive genetic classification of adult acute lymphoblastic leukemia (ALL): analysis of the GIMEMA 0496 protocol. Blood 105: 3434-3441, 2005. 
13. Moorman AV, Harrison CJ, Buck GAN, et al: Karyotype is an independent prognostic factor in adult acute lymphoblastic leukemia (ALL): analysis of cytogenetic data from patients treated on the Medical Research Council (MRC) UKALLXII/Eastern Cooperative Oncology Group (ECOG) 2993 trial. Blood 109: 3189-3197, 2007.

14. Schlenk RF, Benner A, Hartmann F, et al: Risk-adapted postremission therapy in acute myeloid leukemia: results of the German multicenter AML HD93 treatment trial. Leukemia 17: 1521-1528, 2003.

15. Kolitz JE, George SL, Dodge RK, et al: Dose escalation studies of cytarabine, daunorubicin, and etoposide with and without multidrug resistance modulation with PSC-833 in untreated adults with acute myeloid leukemia younger than 60 years: final induction results of Cancer and Leukemia Group B study 9621. J Clin Oncol 22: 4290-4301, 2004.

16. Petersdorf SH, Rankin C, Head DR, et al: Phase II evaluation of an intensified induction therapy with standard daunomycin and cytarabine followed by high dose cytarabine for adults with previously untreated acute myeloid leukemia: a Southwest Oncology Group study (SWOG-9500). Am J Hematol 82: 1056-1062, 2007.

17. Rowe JM, Buck G, Burnett AK, et al: Induction therapy for adults with acute lymphoblastic leukemia: results of more than 1500 patients from the international ALL trial: MRC UKALL XII/ECOG E2993. Blood 106: 3760-3767, 2005.

18. Whitman SP, Archer KJ, Feng L, et al: Absence of the wild-type allele predicts poor prognosis in adult de novo acute myeloid leukemia with normal cytogenetics and the internal tandem duplication of FLT3: a Cancer and Leukemia Group B study. Cancer Res 61: 7233-7239, 2001.

19. Fröhling S, Schlenk RF, Breitruck J, et al: Prognostic significance of activating FLT3 mutations in younger adults (16 to 60 years) with acute myeloid leukemia and normal cytogenetics: a study of the AML Study Group Ulm. Blood 100: 4372-4380, 2002.

20. Fröhling S, Schlenk RF, Stolze I, et al: CEBPA mutations in younger adults with acute myeloid leukemia and normal cytogenetics: prognostic relevance and analysis of cooperating mutations. J Clin Oncol 22: 624-633, 2004.

21. Schnittger S, Schoch C, Kern W, et al: Nucleophosmin gene mutations are predictors of favorable prognosis in acute myelogenous leukemia with a normal karyotype. Blood 106: 3733-3739, 2005.

22. Döhner K, Schlenk RF, Habdank M, et al: Mutant nucleophosmin (NPM1) predicts favorable prognosis in younger adults with acute myeloid leukemia and normal cytogenetics: interaction with other gene mutations. Blood 106: 3740-3746, 2005.

23. Whitman SP, Ruppert AS, Radmacher MD, et al: FLT3 D835/ I836 mutations are associated with poor disease-free survival and a distinct gene-expression signature among younger adults with de novo cytogenetically normal acute myeloid leukemia lacking FLT3 internal tandem duplications. Blood 111: 1552-1559, 2008.

24. Paschka P, Marcucci G, Ruppert AS, et al: Wilms tumor 1 gene mutations independently predict poor outcome in adults with cytogenetically normal acute myeloid leukemia: a Cancer and Leukemia Group B study. J Clin Oncol (In press).

25. Mrózek K, Marcucci G, Paschka P, et al: Clinical relevance of mutations and gene-expression changes in adult acute myeloid leukemia with normal cytogenetics: are we ready for a prognostically prioritized molecular classification? Blood 109: 431-448, 2007.

26. Schnittger S, Kohl TM, Haferlach T, et al: KIT-D816 mutations in AML1-ETO-positive AML are associated with impaired event-free and overall survival. Blood 107: 1791-1799, 2006.

27. Paschka P, Marcucci G, Ruppert AS, et al: Adverse prognostic significance of KIT mutations in adult acute myeloid leukemia with inv(16) and $t(8 ; 21)$ : a Cancer and Leukemia Group B study. J Clin Oncol 24: 3904-3911, 2006.

28. Dicker F, Haferlach C, Kern W, Haferlach T and Schnittger S: Trisomy 13 is strongly associated with $A M L 1 / R U N X 1$ mutations and increased FLT3 expression in acute myeloid leukemia. Blood 110: 1308-1316, 2007.

29. Mrózek K: Cytogenetic, molecular genetic and clinical characteristics of acute myeloid leukemia with a complex karyotype. Semin Oncol (In press).

30. Baldus CD, Thiede C, Soucek S, Bloomfield CD, Thiel E and Ehninger G: BAALC expression and FLT3 internal tandem duplication mutations in acute myeloid leukemia patients with normal cytogenetics: prognostic implications. J Clin Oncol 24: 790-797, 2006
31. Heuser M, Beutel G, Krauter J, et al: High meningioma 1 $(M N 1)$ expression as a predictor for poor outcome in acute myeloid leukemia with normal cytogenetics. Blood 108: 3898-3905, 2006.

32. Marcucci G, Maharry K, Whitman SP, et al: High expression levels of the ETS-related gene, ERG, predict adverse outcome and improve molecular risk-based classification of cytogenetically normal acute myeloid leukemia: a Cancer and Leukemia Group B study. J Clin Oncol 25: 3337-3343, 2007.

33. Lindvall C, Furge K, Björkholm M, et al: Combined genetic and transcriptional profiling of acute myeloid leukemia with normal and complex karyotypes. Haematologica 89: 1072-1081, 2004.

34. Schoch C, Kohlmann A, Dugas M, Kern W, Hiddemann W, Schnittger S and Haferlach T: Genomic gains and losses influence expression levels of genes located within the affected regions: a study on acute myeloid leukemias with trisomy 8,11 , or 13 , monosomy 7, or deletion 5q. Leukemia 19: 1224-1228, 2005.

35. Lee S, Chen J, Zhou G, et al: Gene expression profiles in acute myeloid leukemia with common translocations using SAGE. Proc Natl Acad Sci USA 103: 1030-1035, 2006.

36. Radmacher MD, Marcucci G, Ruppert AS, et al: Independent confirmation of a prognostic gene-expression signature in adult acute myeloid leukemia with a normal karyotype: a Cancer and Leukemia Group B study. Blood 108: 1677-1683, 2006.

37. Andersson A, Ritz C, Lindgren D, et al: Microarray-based classification of a consecutive series of 121 childhood acute leukemias: prediction of leukemic and genetic subtype as well as of minimal residual disease status. Leukemia 21: 1198-1203, 2007.

38. Garzon R, Volinia S, Liu C-G, et al: MicroRNA signatures associated with cytogenetics and prognosis in acute myeloid leukemia. Blood 111: 3183-3189, 2008.

39. Marcucci G, Radmacher MD, Maharry K, et al: MicroRNA expression in cytogenetically normal acute myeloid leukemia. $\mathrm{N}$ Engl J Med 358: 1919-1928, 2008.

40. National Comprehensive Cancer Network: NCCN Clinical Practice Guidelines in Oncology - v.1.2008. Acute Myeloid Leukemia. http://www.nccn.org/professionals/physician_gls/ PDF/aml.pdf. Accessed March 7, 2008.

41. British Committee for Standards in Haematology: Milligan DW, Grimwade D, Cullis JO, et al: Guidelines on the management of acute myeloid leukaemia in adults. Br J Haematol 135: 450-474, 2006.

42. Sandberg AA: The Chromosomes in Human Cancer and Leukemia. 2nd edition. Elsevier, New York, NY, 1990.

43. Mrózek K, Heinonen K and Bloomfield CD: Clinical importance of cytogenetics in acute myeloid leukaemia. Best Pract Res Clin Haematol 14: 19-47, 2001.

44. Johansson B, Mertens F and Mitelman F: Clinical and biological importance of cytogenetic abnormalities in childhood and adult acute lymphoblastic leukemia. Ann Med 36: 492-503, 2004.

45. Mitelman F, Johansson B and Mertens F (eds.): Mitelman database of chromosome aberrations in cancer. 2/2008 update: http://cgap.nci.nih.gov/Chromosomes/Mitelman, 2008.

46. Bloomfield CD, Mrózek K and Caligiuri MA: Cancer and Leukemia Group B Leukemia Correlative Science Committee: major accomplishments and future directions. Clin Cancer Res 12: 3564s-3571s, 2006.

47. Mitelman F (ed.): ISCN (1995): An International System for Human Cytogenetic Nomenclature. Karger, Basel, 1995.

48. Marcucci G, Mrózek K, Ruppert AS, et al: Abnormal cytogenetics at date of morphologic complete remission predicts short overall and disease-free survival, and higher relapse rate in adult acute myeloid leukemia: results from Cancer and Leukemia Group B study 8461. J Clin Oncol 22: 2410-2418, 2004.

49. Farag SS, Archer KJ, Mrózek K, et al: Isolated trisomy of chromosomes $8,11,13$ and 21 is an adverse prognostic factor in adults with de novo acute myeloid leukemia: results from Cancer and Leukemia Group B 8461. Int J Oncol 21: 1041-1051, 2002.

50. Smith A, Watson N and Sharma P: Frequency of trisomy 15 and loss of the Y chromosome in adult leukemia. Cancer Genet Cytogenet 114: 108-111, 1999.

51. Hanson CA, Steensma DP, Hodnefield JM, et al: Isolated trisomy 15: a clonal chromosome abnormality in bone marrow with doubtful hematologic significance. Am J Clin Pathol 129: 478-485, 2008.

52. Mrózek K, Prior TW, Edwards C, et al: Comparison of cytogenetic and molecular genetic detection of $\mathrm{t}(8 ; 21)$ and inv(16) in a prospective series of adults with de novo acute myeloid leukemia: a Cancer and Leukemia Group B study. J Clin Oncol 19: 2482-2492, 2001. 
53. Hoeltge GA, Dewald G, Miles J and Palmer C: Proficiency testing in clinical cytogenetics. The 1986 experience of the College of American Pathologists. Arch Pathol Lab Med 112: 1085-1090, 1988.

54. Hoeltge GA, Dewald G, Palmer CG, et al: Proficiency testing in clinical cytogenetics. A 6-year experience with photographs, fixed cells, and fresh blood. Arch Pathol Lab Med 117: 776-779, 1993.

55. Held K, Eiben B and Miny P: The long-term effect of external quality assessment on performance in service cytogenetics. Cytogenet Cell Genet 91: 124-127, 2000

\section{Appendix}

The following Cancer and Leukemia Group B institutions, principal investigators, and cytogeneticists participated in this study: Wake Forest University School of Medicine, Winston-Salem, NC: David D. Hurd, Harold O. Goodman, P. Nagesh Rao, Wendy L. Flejter and Mark J. Pettenati (grant no. CA03927); North Shore University Hospital, Manhasset, NY: Daniel R. Budman, Natalie B. Kardon and Prasad R.K. Koduru (grant no. CA35279); Roswell Park Cancer Institute, Buffalo, NY: Ellis G. Levine, Avery A. Sandberg and AnneMarie W. Block (grant no. CA02599); The Ohio State University Medical Center, Columbus, OH: Clara D. Bloomfield, Karl S. Theil, Diane Minka and Nyla A. Heerema (grant no. CA77658); Dana-Farber Cancer Institute, Boston, MA: Eric P. Winer, Ramana Tantravahi, Cynthia C. Morton, Leonard L. Atkins and Paola Dal Cin (grant no. CA32291); Duke University Medical Center, Durham, NC: Jeffrey Crawford, Sandra H. Bigner, Mazin B. Qumsiyeh and Barbara K. Goodman (grant no. CA47577); Weill Medical College of Cornell University, New York, NY: John Leonard, Ram S. Verma* Prasad R.K. Koduru, Andrew J. Carroll and Susan Mathew (grant no. CA07968); University of Maryland Cancer Center, Baltimore, MD: Martin Edelman, Joseph R. Testa, Deana Hallman, Stuart Schwartz, Maimon M. Cohen, Judith Stamberg and Yi Ning (grant no. CA31983); University of Iowa Hospitals, Iowa City, IA: Gerald H. Clamon and Shivanand R. Patil (grant no. CA47642); University of Chicago Medical Center, Chicago, IL: Gini Fleming, Diane Roulston, Katrin M. Carlson, Yanming Zhang and Michelle M. Le Beau (grant no. CA41287); University of North Carolina, Chapel Hill, NC: Thomas Shea and Kathleen W. Rao (grant no. CA47559); Washington University School of Medicine, St. Louis, MO: Nancy L. Bartlett, Christine G. Janney, Eric C. Crawford, Jaime Garcia-Heras and Michael S. Watson (grant no. CA77440); Dartmouth Medical School, Lebanon, NH: Marc S. Ernstoff, Doris H. Wurster-Hill* and Thuluvancheri K. Mohandas (grant no. CA04326); Rhode Island Hospital, Providence, RI: William Sikov, Teresita Padre-Mendoza, Jennifer A. Ahearn, Philip L. Townes, Hon Fong L. Mark, Shelly L. Kerman and Aurelia Meloni-Ehrig (grant no. CA08025); University of Alabama at Birmingham: Robert Diasio and Andrew J. Carroll (grant no. CA47545); SUNY Upstate Medical University, Syracuse, NY: Stephen L. Graziano, Navnit S. Mitter, Edward J. Hallinan, Lawrence P. Gordon and Constance K. Stein (grant no. CA21060); Christiana Care Health Services, Inc., Newark, DE: Stephen S. Grubbs, Digamber S. Borgaonkar, Jeanne M. Meck and Kathleen Richkind (grant no. CA45418); University of Missouri/Ellis Fischel Cancer Center, Columbia, MO: Michael C. Perry, Judith H. Miles, Jeffrey R. Sawyer, Tim H. Huang and Linda M. Pasztor (grant no. CA12046); Long Island
Jewish Medical Center CCOP, Lake Success, NY: Kanti R. Rai, Alan L. Shanske and Prasad R.K. Koduru (grant no. CA11028); Minneapolis VA Medical Center, Minneapolis, MN: Vicki A. Morrison and Sugandhi A. Tharapel (grant no. CA47555); University of California, San Diego, CA: Barbara A. Parker, Oliver W. Jones, E. Robert Wassman, Renée Bernstein* and Marie L. Dell'Aquila (grant no. CA11789); Walter Reed Army Medical Center, Washington, DC: Thomas Reid, Rawatmal B. Surana, Syed K. Rafi, Doris H. WursterHill*, Digamber S. Borgaonkar, Karl S. Theil, Diane Minka, Nyla A. Heerema and Kathleen E. Richkind (grant no. CA26806); Parkview Hospital, Ft. Wayne, IN: Sreenivasa Nattam and Patricia I. Bader; University of Minnesota, Minneapolis, MN: Bruce A. Peterson, Betsy A. Hirsch and Diane C. Arthur (grant no. CA16450); Mount Sinai School of Medicine, New York, NY: Lewis R. Silverman and Vesna Najfeld (grant no. CA04457); University of Massachusetts Medical School, Worcester, MA: William W. Walsh, Philip L. Townes, Vikram Jaswaney Kathleen E. Richkind, Michael J. Mitchell and Patricia Miron (grant no. CA37135); Massachusetts General Hospital, Boston, MA: Jeffrey W. Clark, Cynthia C. Morton, Paola Dal Cin and Leonard L. Atkins (grant no. CA 12449); Eastern Maine Medical Center, Bangor, ME: Harvey M. Segal and Laurent J. Beauregard (grant no. CA35406); University of Vermont, Burlington, VT: Hyman B. Muss, Elizabeth F. Allen and Mary Tang (grant no. CA77406); Western Pennsylvania Hospital, Pittsburgh, PA: Richard K. Shadduck and Gerard R. Diggans; University of Illinois, Chicago, IL: David J. Peace, Maureen M. McCorquodale, Kathleen E. Richkind and Valerie Lindgren (grant CA74811); Medical College of Virginia/Virginia Commonwealth University, Richmond, VA: John D. Roberts and Colleen Jackson-Cook (grant no. CA52784); ColumbiaPresbyterian Medical Center, New York, NY: Rose R. Ellison and Dorothy Warburton (grant no. CA12011); Finsen Institute, Copenhagen, Denmark: Nis I. Nissen and Preben Philip; McGill Department of Oncology, Montreal, Quebec: J.L. Hutchison and Jacqueline Emond (grant no. CA31809); University of Puerto Rico School of Medicine, San Juan, PR: Eileen I. Pacheco, Ramana Tantravahi, Cynthia C. Morton, Paola Dal Cin and Leonard L. Atkins; Georgetown University Medical Center, Washington, DC: Minnetta C. Liu and Jeanne M. Meck (grant no. CA77597); SUNY Maimonides Medical Center, Brooklyn, NY: Sameer Rafla and Ram S. Verma* (grant no. CA25119); University of Nebraska Medical Center, Omaha, NE: Anne Kessinger and Warren G. Sanger (grant no. CA77298); Medical University of South Carolina, Charleston, SC: Mark R. Green, Eduardo S. Cantu, G. Shashidhar Pai and Daynna J. Wolff (grant no. CA03927); University of California, San Francisco, CA: Charles J. Ryan, Athena M. Cherry and Kathleen E. Richkind (grant no. CA60138); Southern Nevada Cancer Research Foundation CCOP, Las Vegas, NV: John Ellerton, Oliver W. Jones, E. Robert Wassman, Renée Bernstein* and Marie L. Dell'Aquila (grant no. CA35421); University of Cincinnati Medical Center, Cincinnati, OH: Orlando J. Martelo and Ashok K. Srivastava (grant no. CA47515); Kansas City CCOP, Kansas City, MO: Rakesh Gaur and Linda Cooley; South East Cancer Control Consortium, Winston-Salem, NC: James N. Atkins and Mark J. Pettenati (grant no. CA45808). *Deceased. 